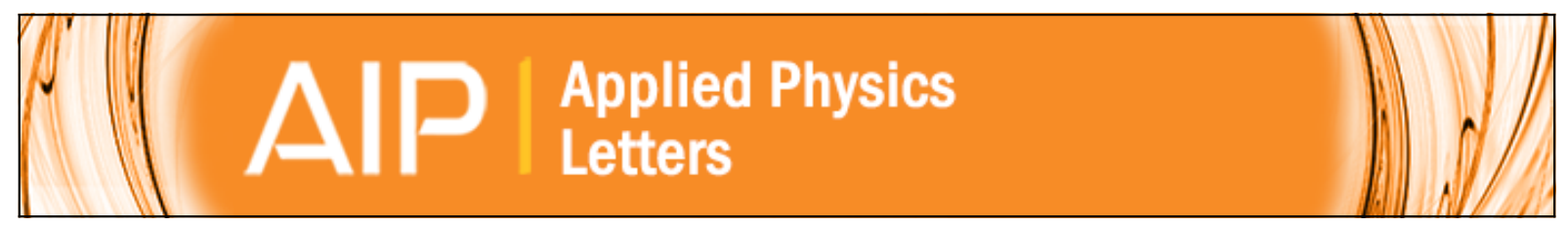

\title{
Thermochemical behavior of hydrogen in hafnium silicate films on $\mathrm{Si}$
}

C. Driemeier, J. J. Chambers, L. Colombo, and I. J. R. Baumvol

Citation: Applied Physics Letters 89, 051921 (2006); doi: 10.1063/1.2335407

View online: http://dx.doi.org/10.1063/1.2335407

View Table of Contents: http://scitation.aip.org/content/aip/journal/apl/89/5?ver=pdfcov

Published by the AIP Publishing

\section{Articles you may be interested in}

Angle-resolved photoelectron study on the structures of silicon nitride films and Si 3 N 4 / Si interfaces formed using nitrogen-hydrogen radicals

J. Appl. Phys. 104, 114112 (2008); 10.1063/1.3002418

Temperature-dependent interfacial chemical bonding states and band alignment of $\mathrm{HfO} \times \mathrm{N}$ y/Si O 2/Si gate stacks

Appl. Phys. Lett. 91, 232910 (2007); 10.1063/1.2813620

Temperature-dependent structural stability and optical properties of ultrathin $\mathrm{Hf}-\mathrm{Al}-\mathrm{O}$ films grown by facing-target reactive sputtering

J. Appl. Phys. 102, 094103 (2007); 10.1063/1.2802994

Effects of the oxygen precursor on the interface between (100)Si and $\mathrm{Hf} \mathrm{O} 2$ films grown by atomic layer deposition

Appl. Phys. Lett. 91, 172905 (2007); 10.1063/1.2802040

Interaction of $\mathrm{HfO} 2 / \mathrm{Si} \mathrm{O} 2 / \mathrm{Si}$ structures with deuterium gas

Appl. Phys. Lett. 88, 041918 (2006); 10.1063/1.2168501

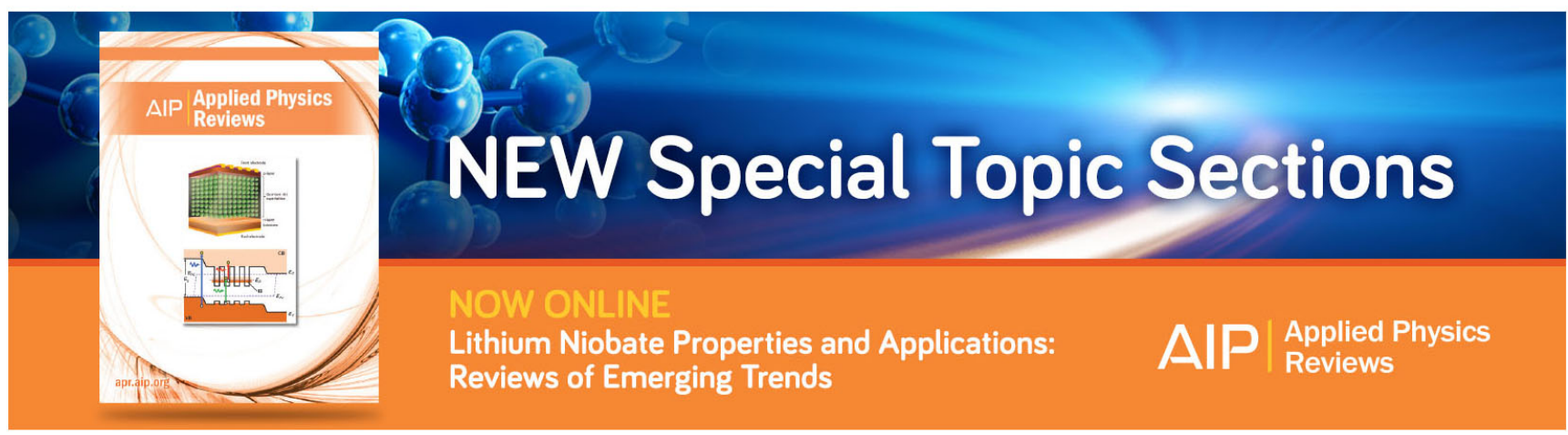




\title{
Thermochemical behavior of hydrogen in hafnium silicate films on $\mathrm{Si}$
}

\author{
C. Driemeier ${ }^{a)}$ \\ Instituto de Física, Universidade Federal do Rio Grande do Sul, Porto Alegre, \\ Rio Grande do Sul 91501-970, Brazil
}

\section{J. J. Chambers and L. Colombo}

Silicon Technology Development, Texas Instruments Incorporated, Dallas, Texas 75243

\author{
I. J. R. Baumvol \\ CCET, Universidade de Caxias do Sul, Caxias do Sul, Rio Grande do Sul 95070-560, \\ Brazil and Instituto de Física, Universidade Federal do Rio Grande do Sul, Porto Alegre, \\ Rio Grande do Sul 91501-970, Brazil
}

(Received 1 May 2006; accepted 21 June 2006; published online 4 August 2006)

\begin{abstract}
$\mathrm{HfSiO}$ films on $\mathrm{Si}$ were sequentially annealed in vacuum, oxygen, hydrogen, or deuterium atmospheres followed by quantification of $\mathrm{H}$ and $\mathrm{D}$ by nuclear reaction analysis. The observed $\mathrm{H}(\mathrm{D})$ incorporation and desorption behaviors are discussed in terms of two $\mathrm{H}$ bonding states in the films. $\mathrm{Si}-\mathrm{H}$ bonds are easier to break thermally and formation of these bonds can be suppressed by annealing in $\mathrm{O}_{2}$ to fully oxidize $\mathrm{Si}$ atoms. $\mathrm{O}-\mathrm{H}$ bonds are harder to break thermally. However, hydrogen atmospheres ease desorption of $\mathrm{H}$ in $\mathrm{O}-\mathrm{H}$ species. The results indicate possible paths to achieve low $\mathrm{H}$ content in $\mathrm{HfSiO}$ gate dielectrics. (c) 2006 American Institute of Physics.
\end{abstract}

[DOI: $10.1063 / 1.2335407$ ]

Materials with high dielectric constants (high- $k$ materials) are being intensively investigated in order to find a replacement for $\mathrm{SiO}_{2}$ as the gate dielectric material in $\mathrm{Si}-$ based metal-oxide-semiconductor field-effect transistors. ${ }^{1,2}$ $\left(\mathrm{HfO}_{2}\right)_{1-x}\left(\mathrm{SiO}_{2}\right)_{x}$ mixed oxides, ${ }^{3,4}$ alternatively called hafnium silicates (HfSiO for short), arose as promising gate dielectric materials because $\mathrm{HfSiO}$ films deposited on $\mathrm{Si}$ holding high dielectric constants while keeping appropriate thermal stability can be achieved. In addition, the presence of hydrogen in gate dielectrics constitutes a key feature, since $\mathrm{H}$ is known to critically influence device properties. Hydrogen at the dielectric/Si interface is necessary to passivate electrically active interfacial $\mathrm{Si}$ dangling bonds. ${ }^{5,6}$ On the other hand, $\mathrm{H}$ in the bulk of gate dielectric films is a potential source of device instabilities ${ }^{7,8}$ and therefore this bulklike $\mathrm{H}$ content must be minimized. Since Hf-based gate dielectrics commonly have $\mathrm{H}$ contents much higher than those found in thermally grown $\mathrm{SiO}_{2},{ }^{9-11}$ understanding the nature of $\mathrm{H}$ incorporation and bonding in HfSiO films as well as developing possible ways to minimize $\mathrm{H}$ content is critical for achieving high quality and reliable $\mathrm{HfSiO}$ gate dielectrics.

We report here on quantitative investigation of hydrogen incorporation, bonding, and thermal stability in $\mathrm{HfSiO}$ films on $\mathrm{Si}$ sequentially annealed in vacuum, oxygen, hydrogen, or deuterium atmospheres. Hafnium silicates were deposited on $\mathrm{Si}(001)$ by metal-organic chemical vapor deposition run at $650{ }^{\circ} \mathrm{C}$ using $\mathrm{Hf}\left[\mathrm{N}\left(\mathrm{C}_{2} \mathrm{H}_{5}\right)_{2}\right]_{4}$ and $\mathrm{Si}\left[\mathrm{N}\left(\mathrm{CH}_{3}\right)_{2}\right]_{4}$ precursors and $\mathrm{O}_{2}$ as oxygen source. $\mathrm{HfSiO}$ films 4, 6, 8, 10, and $50 \mathrm{~nm}$ thick were produced with $30 \%, 60 \%$, or $80 \% \mathrm{SiO}_{2}$ fraction. Channeled Rutherford backscattering spectrometry (not shown) failed to detect $\mathrm{N}$ residuals in the films, indicating $\mathrm{N}$ concentration below 5\% (atomic). Samples were annealed in a Joule-effect heated furnace whose quartz tube was pumped down to a base pressure of $10^{-7}$ mbar. Each annealing was

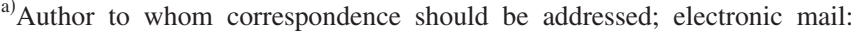
driemeier@if.ufrgs.br performed for $30 \mathrm{~min}$, either in vacuum or in a specific static gaseous atmosphere. Employed atmospheres were 1 mbar of $\mathrm{O}_{2}, 60$ mbars of $\mathrm{D}_{2}\left(\mathrm{H}_{2}\right.$ 95\% enriched in the ${ }^{2} \mathrm{H}=\mathrm{D}$ isotope), or 600 mbars of forming gas $\left(\mathrm{H}_{2}: \mathrm{N}_{2}, 10 \% \mathrm{H}_{2}\right.$, so that $\mathrm{H}_{2}$ partial pressure is also 60 mbars). Vacuum and $\mathrm{O}_{2}$ annealings were performed at $800{ }^{\circ} \mathrm{C}$, while forming gas and $\mathrm{D}_{2}$ annealings were performed at $500{ }^{\circ} \mathrm{C}$. The use of $\mathrm{D}_{2}$ atmospheres is convenient because $\mathrm{D}_{2}$ chemically mimics $\mathrm{H}_{2}$ (forming gas) and also allows to distinguish atoms incorporated from the annealing atmosphere (D) from those previously existing in the films or incorporated from air $(\mathrm{H})$.

Deuterium amounts incorporated into the 4, 6, 8, and $10 \mathrm{~nm}$ thick $\mathrm{HfSiO}$ films annealed in $\mathrm{D}_{2}$ were determined by nuclear reaction analysis ${ }^{12}$ employing $400 \mathrm{keV}^{3} \mathrm{He}^{+}$beams to induce the $\mathrm{D}\left({ }^{3} \mathrm{He}, p\right)^{4} \mathrm{He}$ nuclear reaction. At this energy the cross section of the nuclear reaction is constant (within $3 \%$ ) throughout the films ${ }^{13}$ such that reaction yields are proportional to the total $\mathrm{D}$ amounts in the films. A sensitivity of approximately $10^{12} \mathrm{D} \mathrm{cm}^{-2}$ is achieved. Figure 1(a) shows incorporated $\mathrm{D}$ as a function of film thickness for samples containing $30 \% \mathrm{SiO}_{2}$. Incorporated $\mathrm{D}$ increases linearly with $\mathrm{HfSiO}$ film thickness, evidencing significant $\mathrm{D}$ incorporation in bulk regions of the films. This is in contrast to D incorporation in $\mathrm{HfO}_{2} / \mathrm{Si}$ structures, ${ }^{11}$ where $\mathrm{D}$ was seen incorpo-
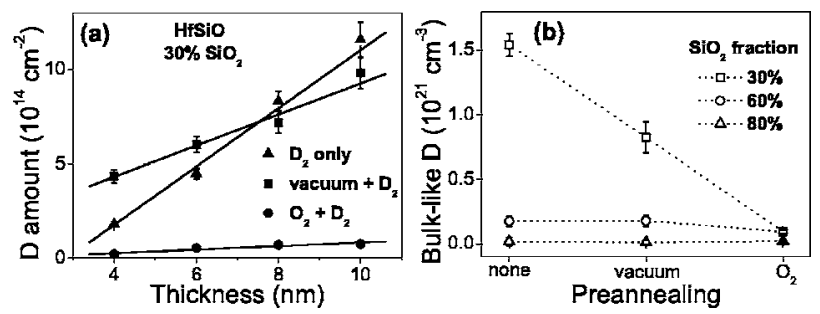

FIG. 1. (a) D amounts vs film thickness for the $30 \% \mathrm{SiO}_{2} \mathrm{HfSiO}$ films after annealing in $\mathrm{D}_{2}$ either with or without preannealing in vacuum or $\mathrm{O}_{2}$. (b) Slopes derived by linear fitting of D amounts vs thickness data for the $30 \%$, $60 \%$, and $80 \% \mathrm{SiO}_{2}$ films. 

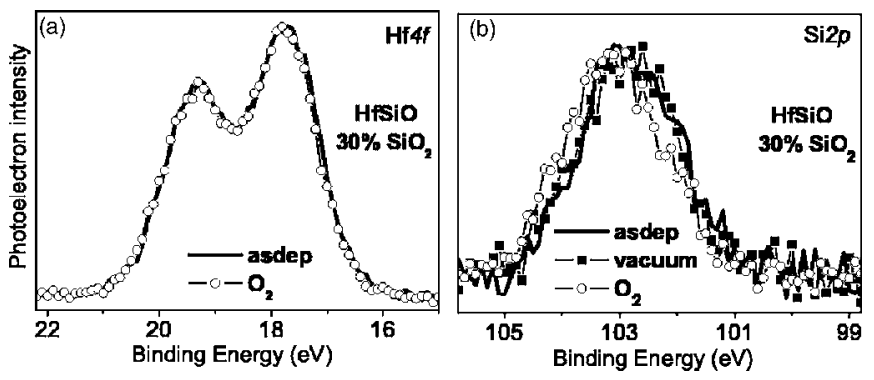

FIG. 2. X-ray photoelectron spectroscopy spectra in the (a) Hf $4 f$ and (b) $\mathrm{Si}$ $2 p$ regions taken from as-deposited and $800^{\circ} \mathrm{C}$-annealed films.

rated mainly in near-surface regions of the $\mathrm{HfO}_{2}$ films, as well as in contrast to $\mathrm{SiO}_{2} / \mathrm{Si}$ structures, where $\mathrm{D}$ incorporates mainly in the $\mathrm{SiO}_{2} / \mathrm{Si}$ interfacial region. ${ }^{12}$

The slopes derived from the linear fitting of the experimental data on D amounts versus HfSiO thickness, expressing the concentration of bulklike D (in units of at. $\mathrm{cm}^{-3}$ ), are shown in Fig. 1(b) for 30\%, 60\%, and $80 \% \mathrm{SiO}_{2}$ films annealed in $\mathrm{D}_{2}$, either with or without preannealing in vacuum or $\mathrm{O}_{2}$. For samples annealed in $\mathrm{D}_{2}$, either with or without vacuum preannealing, one observes an increase of the concentration of bulklike $\mathrm{D}$ with decreasing $\mathrm{SiO}_{2}$ fraction. On the other hand, for $\mathrm{D}_{2}$ annealing performed after preannealing in $\mathrm{O}_{2}$, there is essentially no dependence of incorporated $\mathrm{D}$ on the $\mathrm{SiO}_{2}$ fraction. Moreover, the $30 \% \mathrm{SiO}_{2}$ silicate shows a marked decrease in D incorporation when preannealing was performed prior to $\mathrm{D}_{2}$ exposure, the decrease being more pronounced when preannealing was performed in $\mathrm{O}_{2}$.

The effects of preannealing on film chemistry were accessed by analyzing $10 \mathrm{~nm}$ thick $\mathrm{HfSiO}$ films by x-ray photoelectron spectroscopy. $\mathrm{Mg} K \alpha \mathrm{x}$-ray source and $30^{\circ}$ photoelectron takeoff angle (relative to sample normal) were employed. Figure 2(a) shows Hf $4 f$ photoelectron regions of the as-deposited and $\mathrm{O}_{2}$-annealed $30 \% \mathrm{SiO}_{2}$ films. One observes that the $\mathrm{Hf} 4 f$ peaks do not shift after annealing in $\mathrm{O}_{2}$, indicating no change in the Hf oxidation state. On the other hand, the Si $2 p$ signal shifts $0.3 \mathrm{eV}$ towards higher binding energies after $\mathrm{O}_{2}$ annealing [Fig. 2(b)]. Oxidation of Si substrate cannot be responsible for this shift since the analyzed $10 \mathrm{~nm}$ films are thick enough to attenuate signal coming from the $\mathrm{HfSiO} / \mathrm{Si}$ interface, as evidenced by the absence of $\mathrm{Si}$ substrate signal at $99.6 \mathrm{eV}$. The $\mathrm{Si} 2 p$ signal shift evidences that a significant fraction of the $\mathrm{Si}$ atoms in the $30 \%$ $\mathrm{SiO}_{2}$ silicate film were in suboxidized states, which were converted into fully oxidized $\mathrm{Si}$ during $\mathrm{O}_{2}$ annealing.

We suggest that annealing in $\mathrm{D}_{2}$ forms $\mathrm{Si}-\mathrm{D}$ bonds in these suboxidized $\mathrm{Si}$ atoms. Hence, when $\mathrm{Si}$ atoms become fully oxidized these D incorporation sites are eliminated, resulting in the observed decrease in D incorporation after preannealing in $\mathrm{O}_{2}$ (Fig. 1). For the $60 \%$ and $80 \% \mathrm{SiO}_{2}$ films, shifts in Hf $4 f$ and $\mathrm{Si} 2 p$ signals (not shown) by $\mathrm{O}_{2}$ annealing were below our experimental uncertainty $(0.1 \mathrm{eV})$. These absences of significant shifts in the Si $2 p$ spectra as well as the absences of significant changes in D incorporation after $\mathrm{O}_{2}$ preannealing [Fig. 1(b)] are both related to the absence of significant concentration of suboxidized $\mathrm{Si}$ in these $\mathrm{SiO}_{2}$-richer HfSiO films.

Hydrogen depth profiling in the $50 \mathrm{~nm}$ thick HfSiO films was accomplished using the ${ }^{1} \mathrm{H}\left({ }^{15} \mathrm{~N}, \alpha \gamma\right){ }^{12} \mathrm{C}$ nuclear reaction near the resonance at $6.385 \mathrm{MeV}{ }^{14}$ By progressively in-
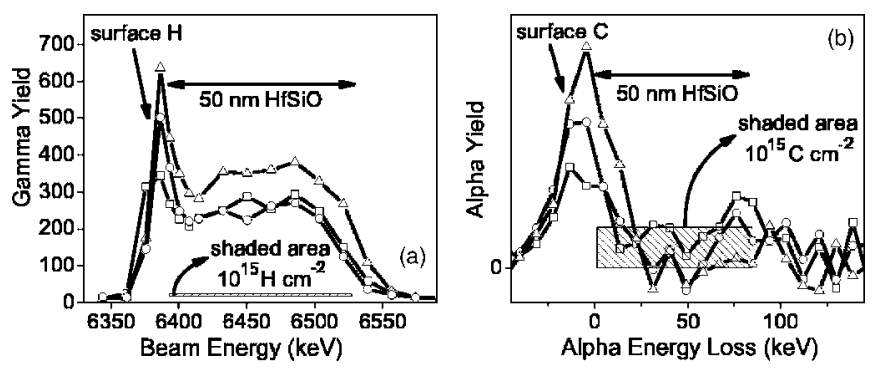

FIG. 3. $\mathrm{H}$ and $\mathrm{C}$ depth sensitive signals from $30 \%, 60 \%$, and $80 \%$ (squares, circles, and triangles, respectively) $\mathrm{SiO}_{2}$ as-deposited $\mathrm{HfSiO}$ films. (a) Excitation curves of the ${ }^{1} \mathrm{H}\left({ }^{15} \mathrm{~N}, \alpha \gamma\right){ }^{12} \mathrm{C}$ nuclear reaction. (b) Alpha spectra of the ${ }^{12} \mathrm{C}(\alpha, \alpha){ }^{12} \mathrm{C}$ elastic nuclear reaction taken from the same samples from (a). Shaded areas corresponding to $10^{15} \mathrm{H} \mathrm{cm}^{-2}$ or $10^{15} \mathrm{C} \mathrm{cm}^{-2}$ are shown for comparison purposes.

creasing the ${ }^{15} \mathrm{~N}$ beam energy above the resonance energy the presence of $\mathrm{H}$ is sampled at progressively deeper layers in the films. Resulting excitation curves [Fig. 3(a)] show a surface peak at the resonance energy, corresponding to $\mathrm{H}$ at sample surface due to exposure to air, whereas signals at higher energies correspond to $\mathrm{H}$ inside the $50 \mathrm{~nm} \mathrm{HfSiO}$ films. By integrating signals corresponding to $\mathrm{H}$ inside the films and comparing with that from a polystyrene standard one derives total $\mathrm{H}$ amounts inside the $50 \mathrm{~nm} \mathrm{HfSiO}$ films to be $(30,28$, and 44$) \times 10^{15} \mathrm{H} \mathrm{cm}^{-2}$ for the $30 \%, 60 \%$, and $80 \% \mathrm{SiO}_{2}$ films, respectively. These $\mathrm{H}$ amounts correspond to average $\mathrm{H}$ concentrations of $(6.0,5.8$, and 8.8) $\times 10^{21} \mathrm{H} \mathrm{cm}^{-3}$, respectively.

In order to investigate whether part of the $\mathrm{H}$ inside the films could be in the form of $\mathrm{C}-\mathrm{H}$ bonds remaining from deposition precursors, we employed the elastic ${ }^{12} \mathrm{C}(\alpha, \alpha){ }^{12} \mathrm{C}$ nuclear reaction $^{15}$ and compared with a $\mathrm{SiC}$ wafer standard to quantify $\mathrm{C}$ in the $\mathrm{HfSiO}$ films. By analyzing the alpha spectra one could separate signal from $\mathrm{C}$ at sample surface (due to air exposure) from $\mathrm{C}$ inside the $50 \mathrm{~nm}$ films [Fig. 3(b)]. C amounts inside the as-deposited $\mathrm{HfSiO} / \mathrm{Si}$ structures are at or below $10^{15} \mathrm{~cm}^{-2}$, which is at least 20 times lower than the determined $\mathrm{H}$ amounts even when uncertainties in $\mathrm{H}$ and $\mathrm{C}$ amounts are taken into account. This implies $\mathrm{C}-\mathrm{H}$ bond breaking during deposition and formation of new bonds between $\mathrm{H}$ and the other elements present in the films. $\mathrm{Hf}-\mathrm{H}$ and $\mathrm{Si}-\mathrm{H}$ bonds are both related to a local oxygen deficiency, since these bonds are replacing, respectively, $\mathrm{Hf}-\mathrm{O}$ and $\mathrm{Si}-\mathrm{O}$ bonds which are the only expected bonds in a stoichiometric, defect-free hafnium silicate. Therefore, both $\mathrm{Hf}-\mathrm{H}$ and $\mathrm{Si}-\mathrm{H}$ bonds tend to be removed by $\mathrm{O}_{2}$ annealing. Since, differently from $\mathrm{Si}$, we could never detect $\mathrm{O}_{2}$-induced changes in $\mathrm{Hf}$ oxidation state (Fig. 2), we suggest that $\mathrm{Hf}-\mathrm{H}$ bonds are a minor contribution to the $\mathrm{H}$ content in the HfSiO films.

${ }^{1} \mathrm{H}\left({ }^{15} \mathrm{~N}, \alpha \gamma\right){ }^{12} \mathrm{C}$ excitation curves before and after annealing at $800{ }^{\circ} \mathrm{C}$ either in vacuum or in $\mathrm{O}_{2}$ are shown in Fig. 4. One observes that the fraction of $\mathrm{H}$ lost during annealing depends on the $\mathrm{SiO}_{2}$ fraction of the HfSiO films, the higher the $\mathrm{SiO}_{2}$ fraction, the lower the $\mathrm{H}$ loss. Previous study in $\mathrm{SiO}_{2}$ (Ref. 16) indicated that $800{ }^{\circ} \mathrm{C}$ annealing for $30 \mathrm{~min}$ completely desorbs $\mathrm{H}$ from $\mathrm{Si}-\mathrm{H}$ bonds while promoting little desorption of $\mathrm{H}$ from $\mathrm{O}-\mathrm{H}$ bonds. This desorption behavior reflects $\mathrm{O}-\mathrm{H}$ bonds being stronger than $\mathrm{Si}-\mathrm{H}$ bonds (typical bond energies are 5.1 and $3.9 \mathrm{eV}$, determined from reference data on the removal of one $\mathrm{H}$ atom from water and silane molecules, respectively). Hence, we attribute $\mathrm{H}$ loss 

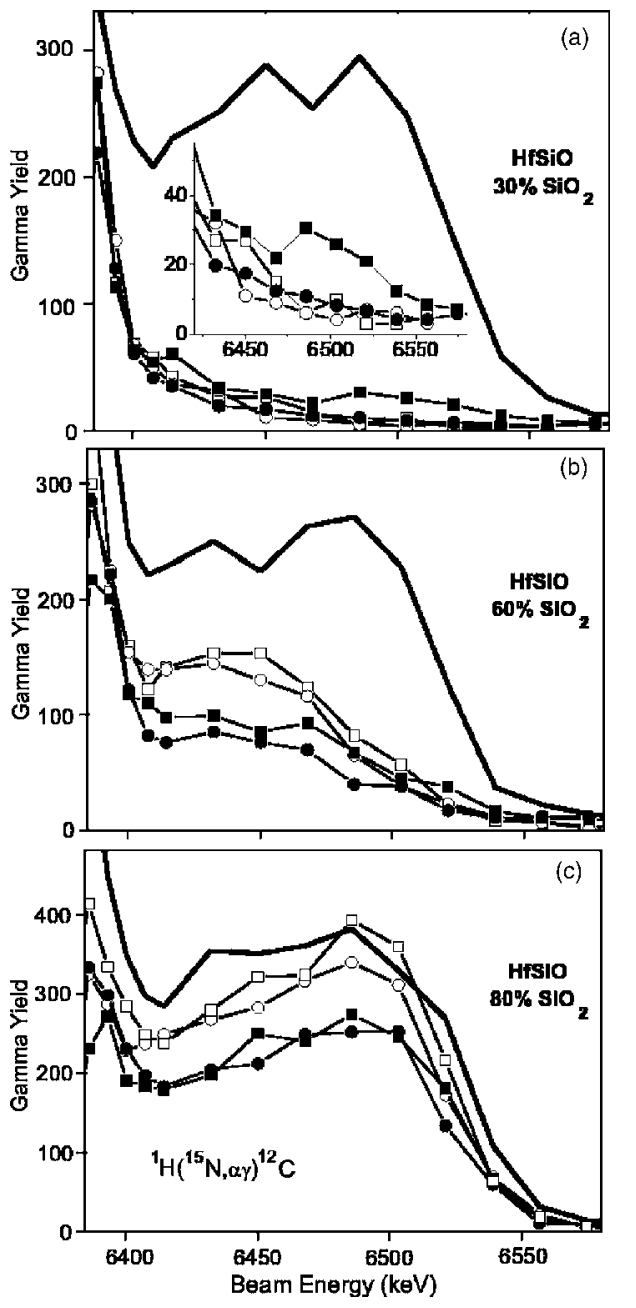

FIG. 4. Excitation curves of the ${ }^{1} \mathrm{H}\left({ }^{15} \mathrm{~N}, \alpha \gamma\right){ }^{12} \mathrm{C}$ nuclear reaction for asdeposited (solid lines) and annealed $50 \mathrm{~nm}$ HfSiO films. Annealing was performed in vacuum (squares) or $\mathrm{O}_{2}$ (circles) either followed by $\mathrm{H}_{2}$ annealing (solid symbols) or not (empty symbols). The horizontal scale is chosen so as to show only signal coming from $\mathrm{H}$ inside the $\mathrm{HfSiO}$ films.

during this $800{ }^{\circ} \mathrm{C}$ annealing to be mainly due to breakage of $\mathrm{Si}-\mathrm{H}$ bonds.

Moreover, the observed $\mathrm{H}$ losses (Fig. 4) were higher in the corresponding silicates where higher $\mathrm{D}$ incorporation was observed [see Fig. 1(b)], which can be justified by the fact that $\mathrm{H}$ loss and $\mathrm{D}$ incorporation are both related mainly to the dissociation and formation of $\mathrm{Si}-\mathrm{H}(\mathrm{D})$ bonds. One can speculate that the existence of more $\mathrm{Si}-\mathrm{H}$ bonds in films with lower $\mathrm{SiO}_{2}$ fraction (and, therefore, less $\mathrm{Si}$ atoms), which is counterintuitive, is so because lower $\mathrm{SiO}_{2}$ fraction (or, alternatively, higher $\mathrm{HfO}_{2}$ fraction) would lead to increasing tendency of $\mathrm{O}$ deficiencies to move towards $\mathrm{Si}$ atoms. Such tendency was observed in phase-separated $\mathrm{HfO}_{2} / \mathrm{SiO}_{2}, 17,18$ where $\mathrm{O}$ deficiencies tend to move towards the $\mathrm{SiO}_{2}$ side of $\mathrm{HfO}_{2} / \mathrm{SiO}_{2}$ interfaces. Nevertheless, this tendency of increasing $\mathrm{Si}-\mathrm{H}$ for decreasing $\mathrm{SiO}_{2}$ concentrations cannot be extrapolated to bulk $\mathrm{HfO}_{2}$, where there are no $\mathrm{Si}$ atoms and, not surprisingly, no D incorporation was observed. ${ }^{11}$

Incorporation of $\mathrm{H}$ by annealing $30 \% \mathrm{SiO}_{2}$ samples in $\mathrm{H}_{2}$ (forming gas) after either vacuum or $\mathrm{O}_{2}$ preannealing [Fig. 4(a)] is consistent with $\mathrm{D}$ incorporation after the same preannealing (Fig. 1). However, for the higher $\mathrm{SiO}_{2}$ silicates one also observes $\mathrm{H}$ loss by annealing in $\mathrm{H}_{2}$. It is interesting to note that $\mathrm{H}$ desorbed by annealing in $\mathrm{H}_{2}$ at $500{ }^{\circ} \mathrm{C}$ could not be previously desorbed in vacuum or $\mathrm{O}_{2}$ at $800{ }^{\circ} \mathrm{C}$, indicating that the $\mathrm{H}_{2}$ atmosphere eases the desorption process. We suggest that this $\mathrm{H}$ desorbed with the help of the $\mathrm{H}_{2}$ atmosphere is in the form of $\mathrm{O}-\mathrm{H}$ groups. This assignment is consistent with the observed resistance for thermal desorption (in vacuum) of $\mathrm{H}$ in the form of $\mathrm{O}-\mathrm{H}$ groups inside $\mathrm{SiO}_{2} \cdot{ }^{16}$ Moreover, differently from $\mathrm{Si}-\mathrm{H}$ bonds which are related to a local $\mathrm{O}$ deficiency, $\mathrm{O}-\mathrm{H}$ bonds are related to a local $\mathrm{Si}$ or Hf deficiency, or, alternatively, O excess. This reasoning relating $\mathrm{O}-\mathrm{H}$ bonding to local $\mathrm{O}$ excess helps in understanding the observed role of the reducing $\mathrm{H}_{2}$ atmosphere on $\mathrm{H}$ desorption. We speculate that the desorption reaction taking place is $\mathrm{H}_{2}+2 \mathrm{OH} \rightarrow 2 \mathrm{H}_{2} \mathrm{O}$. The $\mathrm{H}_{2} \mathrm{O}$ products desorb, resulting in no remaining $\mathrm{H}$ in sites where there was an $\mathrm{O}-\mathrm{H}$ group.

In summary, the $\mathrm{H}$ content in hafnium silicate films on $\mathrm{Si}$ was investigated by nuclear reaction analysis as a function of the postdeposition annealing to which the $\mathrm{HfSiO}$ films were exposed to. Based on the response of the $\mathrm{H}$ content to the annealing atmospheres we described two different $\mathrm{H}$ bonding states with different thermal behaviors. $\mathrm{Si}-\mathrm{H}$ bonds form on suboxidized $\mathrm{Si}$ atoms and $\mathrm{H}$ in these bonds can be desorbed by an $800{ }^{\circ} \mathrm{C}, 30 \mathrm{~min}$ anneal. These $\mathrm{H}$ binding sites are eliminated after fully oxidation of $\mathrm{Si}$ atoms by annealing in $\mathrm{O}_{2}$, leading to lower $\mathrm{H}$ incorporation after $\mathrm{O}_{2}$ preannealing. On the other hand, $\mathrm{H}$ in $\mathrm{O}-\mathrm{H}$ bonds are more resistant to thermal desorption, probably reflecting stronger bonding. Nevertheless, by employing a $\mathrm{H}_{2}$ atmosphere, desorption of $\mathrm{H}$ in $\mathrm{O}-\mathrm{H}$ groups is eased. These results indicate that by appropriately managing postdeposition annealing atmospheres $\mathrm{HfSiO}$ films with low $\mathrm{H}$ content can be achieved.

${ }^{1}$ High- $\kappa$ Gate Dielectrics, edited by M. Houssa (IoP, London, 2004).

${ }^{2}$ G. D. Wilk, R. M. Wallace, and J. M. Anthony, J. Appl. Phys. 89, 5243 (2001).

${ }^{3}$ G. D. Wilk, R. M. Wallace, and J. M. Anthony, J. Appl. Phys. 87, 484 (2000).

${ }^{4}$ G. D. Wilk and R. M. Wallace, Appl. Phys. Lett. 74, 2854 (1999).

${ }^{5}$ K. L. Brower, Phys. Rev. B 38, 9657 (1988).

${ }^{6}$ A. Stesmans and V. V. Afanas'ev, Appl. Phys. Lett. 82, 4074 (2003).

${ }^{7}$ B. J. Mrstik and R. W. Rendell, IEEE Trans. Nucl. Sci. 38, 1101 (1991).

${ }^{8}$ M. Houssa, V. V. Afanas'ev, A. Stesmans, and M. M. Heyns, Appl. Phys. Lett. 77, 1885 (2000).

${ }^{9} \mathrm{~J}$. Krauser, A. Weidinger, and D. Bräuning, in The Physics and Chemistry of $\mathrm{SiO}_{2}$ and of the $\mathrm{Si} / \mathrm{SiO}_{2}$ Interface 3, edited by $\mathrm{H}$. Z. Massoud, $\mathrm{E} . \mathrm{H}$. Poindexter, and C. R. Helms (Electrochemical Society, Pennington, NJ, 1996), Vol. 96-1, pp. 59-71.

${ }^{10}$ R. P. Pezzi, L. Miotti, K. P. Bastos, G. V. Soares, C. Driemeier, I. J. R. Baumvol, P. Punchaipetch, G. Pant, B. E. Gnade, R. M. Wallace, A. Rotondaro, J. M. Visokay, J. J. Chambers, and L. Colombo, Appl. Phys. Lett. 85, 3540 (2004).

${ }^{11}$ C. Driemeier, L. Miotti, I. J. R. Baumvol, C. Radtke, E. P. Gusev, M. J. Kim, and R. M. Wallace, Appl. Phys. Lett. 88, 041918 (2006).

${ }^{12}$ I. J. R. Baumvol, E. P. Gusev, F. C. Stedile, F. L. Freire, Jr., M. L. Green, and D. Brasen, Appl. Phys. Lett. 72, 450 (1998).

${ }^{13}$ W. Möller and F. Besenbacher, Nucl. Instrum. Methods 168, 111 (1980).

${ }^{14}$ G. Amsel, C. Cohen, and B. Maurel, Nucl. Instrum. Methods Phys. Res. B 14, 226 (1986).

${ }^{15}$ M. Östling, C. S. Petersson, and G. Possnert, Nucl. Instrum. Methods Phys. Res. 218, 439 (1983).

${ }^{16}$ S. M. Myers, J. Appl. Phys. 61, 5428 (1987).

${ }^{17}$ M. Copel and M. C. Reute, Appl. Phys. Lett. 83, 3398 (2003).

${ }^{18}$ W. L. Scopel, A. J. R. da Silva, W. Orellana, and A. Fazzio, Appl. Phys. Lett. 84, 1492 (2004). 